\title{
Quality of life in primary caregivers of patients with cerebrovascular disease
}

\author{
Silvia D. Pérez-Villalva ${ }^{1}$, Teresita Villaseñor-Cabrera ${ }^{2,3}, M^{a}$ G. Ramírez-Contreras ${ }^{4}$, \\ Genoveva Rizo-Curie/3,5, and José L. Ruiz-Sandoval3,6*
}

${ }^{1}$ Departamento de Neurociencias, Centro Universitario de Ciencias de la Salud, Universidad de Guadalajara; ${ }^{2}$ Servicio de Neuropsicología, Hospital Civil de Guadalajara, "Fray Antonio Alcalde"; ${ }^{3}$ Departamento de Neurociencias, Instituto de Neurociencias Traslacionales, Centro Universitario de Ciencias de la Salud, Universidad de Guadalajara; "Departamento de Salud Poblacional del Centro Universitario de Tonalá, Universidad de Guadalajara; ${ }^{5}$ Departamento de Salud Pública, Centro Universitario de Ciencias de la Salud, Universidad de Guadalajara; ${ }^{6}$ Servicio de Neurología, Hospital Civil de Guadalajara, "Fray Antonio Alcalde". Guadalajara, Jalisco, Mexico

\begin{abstract}
Stroke is the leading cause of motor and neuropsychological disability in adults worldwide, requiring a primary caregiver (PC) during rehabilitation. The relationship between $P C$ and a patient with cerebrovascular sequelae (PC-PCVD) is complex and bidirectional. Indeed, literature shows a serious deterioration in the PC's quality of life during the follow-up. Through a narrative review of articles published in the last 20 years, this study aims to know the quality of life of PC-CVD, analyze the determinants of the vulnerability of PC-PCVD, and identify the most used test. PC-PCVD was found to have a lower-than-expected quality of life in physical and emotional domains. Being a woman, single, of mayor age, $3 \mathrm{~h}$ of daily care, limited income, and symptoms of anxiety or depression were the main risk factors associated with lower quality of life among PCs. The main assessment tools of quality of life were the World Health Organization Quality of Life BREF and the SF-36 Health Survey.
\end{abstract}

Key words: Caregiver. Main caregiver. Quality of life. Stroke.

\section{Calidad de vida en cuidadores primarios de pacientes con enfermedad vascular cerebral}

\section{Resumen}

La enfermedad vascular cerebral (EVC) es la principal causa de discapacidad motora y neuropsicológica en adultos a nivel mundial, demandando en el proceso de su rehabilitación la presencia de un cuidador primario (CP). La interacción del CP con el paciente con secuelas de EVC (CP-PEVC) es compleja y de acuerdo a evidencias recientes es además bidireccional. De hecho, la mayoría de la información coincide en un deterioro grave en la calidad de vida de los CP durante el seguimiento. Mediante una revisión narrativa de artículos publicados en la literatura en los últimos 20, el presente trabajo tuvo como objetivos conocer la calidad de vida del CP-PEVC, analizar los factores que determinan su vulnerabilidad e identificar las principales pruebas en la evaluación de su calidad de vida. Se encontró que los CP-PEVC presentan niveles de calidad de vida por debajo de lo esperado, específicamente en dominios físico y emocional. Ser mujer, soltera, de mayor edad, con al menos tres horas de cuidado diarios, con ingresos económicos limitados y síntomas de ansiedad o depresión fueron los principales factores de riesgo asociados a menor calidad de vida en los CP. Las principales pruebas utilizadas fueron el World Health Organization quality of Life BREF (WHOQOL-BREF) y el Short Form 36 Health Survey Questionnaire (SF-36 Health Survey).

Palabras clave: Calidad de vida. Cuidador. Cuidador primario. Enfermedad vascular cerebral.

\section{Correspondence:}

*José L. Ruiz-Sandoval

E-mail: jorulej-1nj@prodigy.net.mx
Available online: 15-11-2021 Rev Mex Neuroci. 2021;22(6):229-237 www.revmexneurociencia.com 2604-6180/ @ 2021 Academia Mexicana de Neurología A.C. Published by Permanyer. This is an open access article under the CC BY-NC-ND license (http://creativecommons.org/licenses/by-nc-nd/4.0/). 


\section{Introduction}

Cerebrovascular disease (CVD), either ischemic or hemorrhagic, represents the second cause of death in developed countries and the first cause of disability in adults worldwide'. Over $90 \%$ of CVD survivors have several consequences, while $30-50 \%$ present disability for activities of daily living, both basic and instrumentals $^{2,3}$, these patients require a sophisticated infrastructure and organization by the health system, as well as the participation of competent community personnel and family members or primary caregivers (PC) at home.

The PC plays a key role in the rehabilitation of patients with CVD. However, due to the absence - in the worst case - or failures and inconsistencies in the hospital or out-of-hospital support network, it is possible that the burden of PC is excessively high and produces stress, anxiety, depression, sleep disorders, physical pain, and poor quality of life.

The complex concept of quality of life quality was introduced since the 1980s. It was defined by the United Nations Organization ${ }^{4}$ as the perception of an individual about his position in life, in the context of his culture and his value system and about his goals, expectations, standards, and concerns; however, there is heterogeneity of definitions and therefore, each author describes various components or domains for this concept.

The analysis of the quality of life of both the patient with CVD and the caregiver favors the understanding of the impact it has on other aspects of cerebral vascular disease that are not usually addressed. In this narrative review, it is intended to answer the following questions: (a) which are the affected quality of life domains in the PC of CVD patients (PC-PCVD)?; (b) what factors determine the level of quality of life of PC-PCVD?; and (c) what are the most used instruments in the evaluation of quality of life for PC-PCVD?

\section{Methods}

This article is based on unsystematic research in Google Scholar and PubMed for original manuscripts about: "Cerebral Vascular Disease," "Cerebrovascular Disease," "Cerebral vascular accident," "Stroke," "Cerebral infarction," "Intracerebral hemorrhage," "Caregiver," " PC," and "Caregiver quality of life" followed for a discretionary selection of publications. Some of the references used as "clinical evidence sources" are commented on the reference list.
The inclusion criteria were: (a) studies published between 2000 and 2020; (b) Spanish or English language; (c) general or specific objective was to analyze the quality of life of PC-PCVD and/or to find the determinants of quality of life, (d) publications with CVD of ischemic disease (cerebral infarction) or hemorrhagic disease (intracerebral hemorrhage).

The exclusion criteria were: (a) studies of paid caregivers and (b) reviews of the literature, reflections, or editorial notes on the subject.

The information analysis was about content. It was carried out with the help of tables, where each article was categorized by objective, year, sample size, methodology, and conclusion.

\section{Results}

During the period of the last 20 years, 244 eligible abstracts were identified. However, only 28 articles were selected according to the inclusion and exclusion criteria described above. Indeed, figure 1 explains the complete selection process for this non-systematic review.

Out of the 28 articles, only 3 articles were published in Spanish and were developed in Colombia and Spain. On the other hand, the 25 English articles were directed in countries as Sweden, the United States, Canada, Mongolia, Japan, China, Korea, Portugal, Brazil, Ireland, and Italy.

To accomplish the objectives, the results of this analysis are presented in three different sections: (I) quality of life of PCs of patients with cardiovascular disease, (II) determinants of quality of life in PC of patients with cerebrovascular disease, and (III) quality of life tests more frequently used in evaluating $\mathrm{PC}$ of patients with CVD.

Besides, it is essential to establish that due to the heterogeneity in the methods (study designs and tests) of the reviewed articles, there are not specified numerical values of the performances of neither the caregivers nor patients.

\section{Quality of life of PC of patients with cerebrovascular disease}

In a Swedish study, the quality of life of PC of patients with ischemic $(89.1 \%)$, hemorrhagic $(10.6 \%)$, and undefined $(0.3 \%)$ CVD was compared at 4 and 16 months $^{5}$. The Short Form 36 Health Survey Questionnaire (SF-36) was used to assess eight domains through subjective personal perception: physical functioning (degree of limitation on activities of daily living due to physical health); physical role (limitations on instrumental and work 


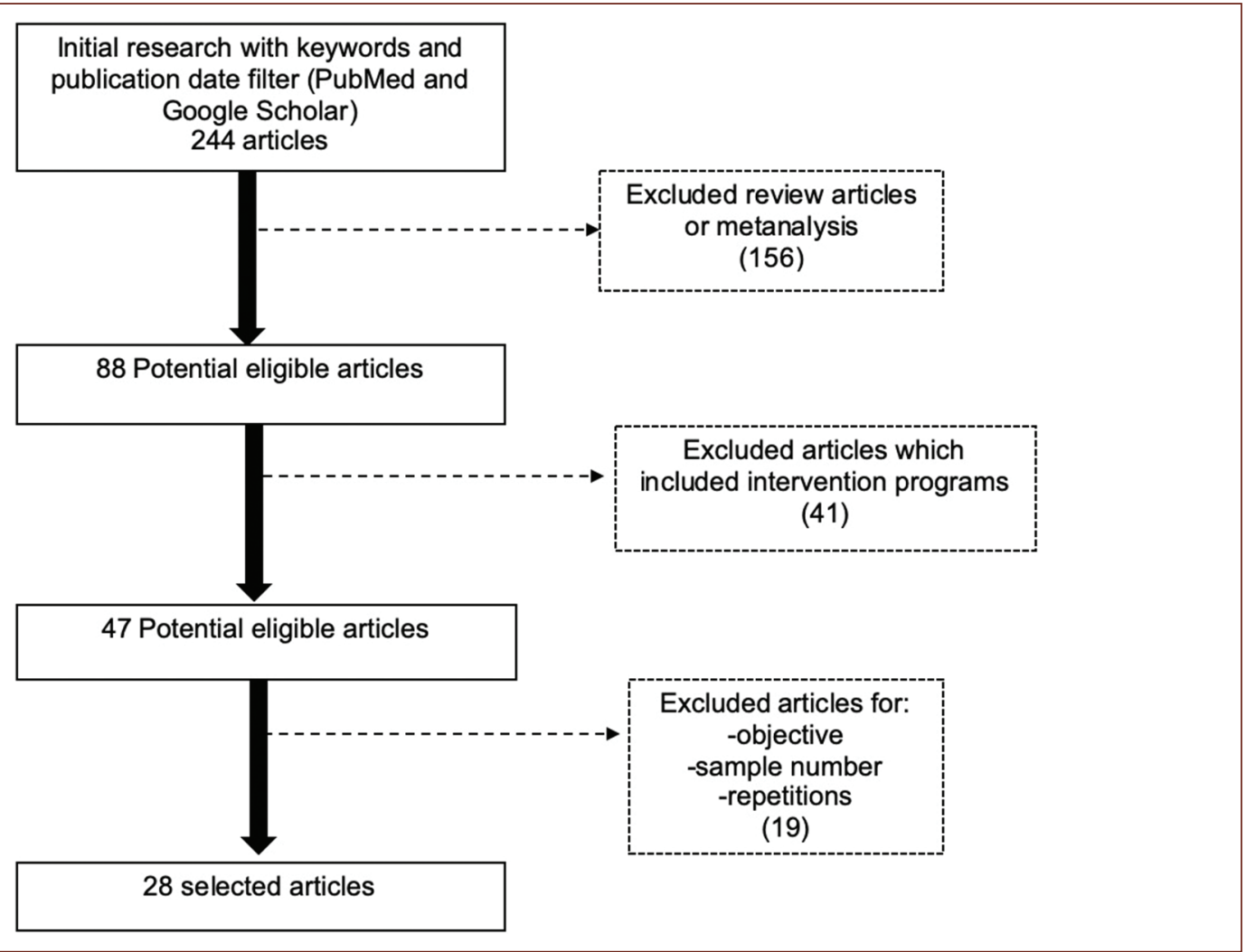

Figure 1. Diagram of the selection process of the articles.

activities due to alterations in physical health); bodily pain (limitation due to physical pain); general health (includes the perspective of health and resistance to illness); vitality (amount of energy); social functioning (degree of social life impact); emotional role (level at which emotional difficulties affect daily and work activities); and mental health (depressive symptoms, anxiety, behavioral and emotional disturbances). Each domain is scored from 0 to 100 , with the highest score meaning better quality of life ${ }^{6}$.

Overall, caregivers scored better than patients in the short and long term, with the exception of the emotional role domain, which was the only domain with a significantly lower performance for $\mathrm{PC}^{5}$.

With the support of the same assessment instrument, and therefore, following the same theoretical aspects of quality of life, McPherson et al., in a Canadian study, found out that when comparing the quality of life of ischemic $(71 \%)$, hemorrhagic (25\%), and mixed $(4 \%)$ PC-PCVD with the non-caregiver subjects from the normative sample of the SF-36 Health Survey, there was a lower score in all eight domains among caregivers. Although, the most significant were physical role, physiological functioning, and emotional role?
Another study conducted in the United States compared the well-being of PC-PCVD (92\% ischemic, $2 \%$ hemorrhagic) versus non-caregivers after 3 years of follow-up. Well-being was considered as the absence of depressive symptoms, quality of life (physical and mental aspects), and satisfaction with life and with leisure activity. Evaluations were obtained at nine, 18, 27, and 36 months. At 9 months, PC-PCVD performed lower than controls in every expected area in the quality of life physical domain. Likewise, at long-term evaluation, it is shown an improvement in the physical domain but without reaching the same level as non-caregivers. However, satisfaction with leisure activity was persistently low during the 3 years for PC-PCVD.

In Mongolia, Chuluunbaatar et al. carried out a quality of life study in PC-PCVD of ischemic (58\%) and hemorrhagic (42\%) types, in the acute phase at 7 and 10 days and at 12 months considering four domains: physical health, psychological health, social relationship, and environmental domain. This study showed that during the first year, caregivers improved significantly in the psychological health and environmental domain, but not in physical health. In other words, at the acute phase, caregivers tend to suffer a physical damage; however, 
they seem to adapt by having more positive feelings, better concentration, higher self-esteem, higher spirituality, better self-perception, more social assistance, effective use of financial resources, ease of transportation, and broader knowledge of the disease ${ }^{9}$.

An additional study from Pucciarelli et al. (2017) considered the same four quality of life domains. This investigation evaluated $\mathrm{PC}$ and patients with ischemic $(80 \%)$ and hemorrhagic CVD $(20 \%)$ in the acute phase and at 12 months follow-up. The findings were that in the acute phase both caregivers and patients showed lower than expected quality of life level, although caregivers had a better quality of life than patients. At 12 months, patients improved in both physical and psychological health aspects, while caregivers continued to have a better quality of life ${ }^{10}$.

In Latin America, there is a work published in Colombia in 2010, which evaluatedPC-PCVD through the Ferrel scale, which divides quality of life into four aspects: physical, psychological, social, and spirituality ${ }^{11}$. This study found out greater deterioration in physical and social aspects in most PC, specifically sleep disturbance and fatigue, as well as insufficient support from others and disturbances in personal relationships. On the contrary, the least affected area was spiritual domain ${ }^{12}$.

Moreover, an Asian study in Malaysia compared the quality of life of PC and PCVD (93.3\% ischemic and $6.7 \%$ hemorrhagic). It reported that caregivers had a better quality of life than the patients ${ }^{13}$. However, a Japanese project reported greater impairment of quality of life in PC than in patients with unspecified CVD ${ }^{14}$.

\section{Determinants of quality of life in PC of patients with cerebrovascular disease}

\section{GENDER}

Women caregivers have been reported to have higher levels of burden and depression than men. In fact, it has been reported that women caregivers have greater difficulty in asking for help and support and that they often spend more hours caring for patients with $C V D^{9,15}$. Furthermore, it has also been found that the longer the caring times, the greater quality of life for CVD survivors (mainly in the ischemic type). In other words, being a woman seems to be a factor of vulnerability as a caregiver, but a protective factor for the patient ${ }^{16}$.

However, other findings suggest that male caregivers are related to worst PC quality of life in specific areas such as energy/vitality and mental health ${ }^{5}$. It is important to note that being a woman seems to be a risk factor for the low quality of life as PC, but it is essential to highlight that this finding may be due to the majority are women caregivers' cases in most of the studies ${ }^{17,18}$.

\section{AgE}

In addition to the sex of the PC, age has been also identified as a determining factor in their own quality of life. Some studies indicate that younger age of the patient and caregiver determines a better quality of life in favor of $P C^{5,7}$. It has been described more specifically that those caregivers over 60 years old are more likely to have a low quality of life scores. However, it has also been stated that those caregivers under 40 years of age present a greater complaint of physical pain compared to older people ${ }^{17}$. On the other hand, there are some studies where no correlation between the age of PC and quality of life has been found ${ }^{19}$.

\section{TIME OF CARE}

Some evidence highlights the negative effect of a higher number of caring hours on the PC-PCVD quality of life. These findings are of great relevance since they not only refer to the investment of time and fatigue due to the long day of care but also highlight the reduction of time dedicated to other activities as resting and recreation by the $\mathrm{PC}$, showing they have higher levels of frustration and depressive symptoms ${ }^{20}$.

In this way, other studies have provided information on the impact of hours of care on the burden and low quality of life of $\mathrm{PC}$, considering it a risk factor for mental health ${ }^{18}$. In fact, it has been specifically described that caregivers with more than $3 \mathrm{~h}$ of care per day have worse performance in most of the determinants of quality of life ${ }^{21}$, while those who work as caregivers 12 or more hours per day have worse performance and a significant deterioration in all quality of life aspects ${ }^{22}$.

However, not only the hours of care per day matter but also the intensity of it. In other words, spending several days or months taking care of a patient with CVD without a rest period has also been assessed. It is shown that at 1-year post-CVD-without specifying the type-no significant differences in quality of life have been found, inferring that the negative impact on quality of life from the PC occurs in the first 12 months ${ }^{22,23}$.

\section{EMPLOYMENT/FINANCIAL SITUATION}

There are direct or indirect costs caused by CVD in the medium or long term. By example, the costs of care, 
rehabilitation, secondary prevention, partial or total disability, loss of productive activities, among others. These costs are relevant for the patient, for the health care system, and also for the family, including caregivers $^{24}$. However, this aspect has been scarcely studied in the literature.

Unemployed PC has a lower quality of life compared to their peers, greater burden, and a negative impact on mental health ${ }^{25}$. This finding is relevant, considering that the majority of the caregiving wives of patients with CVD are unemployed or retired ${ }^{17}$. Additional information highlights that $36 \%$ of PC with current employment were reassigned or looked for another job because to care for their relative; this occurred between the $3^{\text {rd }}$ and $9^{\text {th }}$ month after $C V D^{26}$.

In a 2013 Brazilian study, it was found that PC-PCVD non-specified type, regardless of gender, obtained one to three minimum monthly wages (678-2,034 Brazilian real's or 4,109-12,329 Mexican pesos). This income was explained by the need for part-time jobs and/or with minimal school demands and flexible schedules ${ }^{17}$.

The anxiety generated by the reduction or lack of economic income has been associated with a lower score in the quality of life; this affects the vitality and mental health of $P C^{9,17}$. This generates a vicious circle because low levels of quality of life are associated with the hospital readmission of the patient who does not have medical insurance, and therefore expenses have a negative impact on the family economic situation ${ }^{27}$.

In 2012, it was reported that those PC that lives in rural areas have a lower quality of life. This is mainly explained by the difficulty of accessing social and medical support ${ }^{28}$. Furthermore, a relationship between the economic situation and the educational level exists. In the case of PC patients with chronic diseases and dependence, it has been identified that a high educational level determines a better quality of life in caregivers ${ }^{29}$.

\section{RELATIONSHIP AND MARITAL STATUS}

Delcourt et al. analyzed the interaction of ischemic and hemorrhagic PC-PCVD and marital status, observing that married caregivers had a better quality of life. This was due to a better support network and/or perception of support ${ }^{30}$. Likewise, Costa et al. found that being the patient's spouse was reflected in a better quality of life, specifically in mental health ${ }^{17}$.

In contrast, other studies have described that single caregivers have a better quality of life; this indicates that married PC with children have worse scores in the measurement of quality of life ${ }^{21}$.
Being the spouse of a patient with an ischemic stroke guarantees functional improvements at 1 year of follow-up at the cost of a decrease in the quality of life of the spouse ${ }^{31}$. However, in another comparative study between spousal and non-spousal caregivers of patients with unspecified CVD during the first 2 months, it was found that the four aspects of quality of life evaluated with better scores were obtained by the spouses of patients with CVD. The aspects evaluated were: physical health, psychological health, social and environment relationships, particularly in the section on social relationships, there were higher scores ${ }^{32}$.

Regardless of the relationship that exists between the PC and the patient, cohabitation gives higher scores in the quality of life ${ }^{33}$.

\section{ANXIETY/DEPRESSION}

Mood, anxiety, and depression disorders have been studied in PC due to their strong relationship with quality of life. In fact, there are significant correlations between the mental component of quality of life and symptoms of anxiety and depression ${ }^{21}$. Furthermore, it has been reported that around a fifth of PC suffers from anxiety, while a quarter suffers from depresión ${ }^{34}$. Indeed, equivalent depression and anxiety scores have been found between PC and patients, indicating that the psychological sequelae of CVD affect both PC and the patient because of an effect called "emotional contagion"13.

More precisely, Wan-Fei et al. found that high levels of depression in PC-PCVD, both ischemic and hemorrhagic, have an impact on their own quality of life, specifically in physical appearance, lower vitality, and limitations in daily life due to his physical health. In this same study, high levels of anxiety among caregivers had a strong impact on their quality of life, being more significant in mental aspects, greater limitation in life activities, and less social coexistence, among others ${ }^{13}$. The presence of pain, depressed mood, and burden has been associated with a poorer quality of life in PC-PCVD of unspecified type ${ }^{18}$.

\section{Patients disability}

Any type of CVD could be the cause of diverse sequelae among patients, highlighting motor and speech disorders as the most frequent. Nowadays, it is known that the greater the physical dependence of the patient, the lower the quality of life of the $P C^{5,33}$. Likewise, it has been found that the greater the severity of the patients sequelae and their inability to communicate, the 
PC will present lower scores than expected in the mental health components in the quality of life construct ${ }^{21,20}$. It is also recognized that a poor social interaction on the part of the patient negatively affects the quality of life of his $\mathrm{PC}^{5}$.

Regarding cognitive and psycho-affective sequelae in patients with CVD, it has been described that the greater the cognitive deterioration and the greater the perception of alterations in mental functions by the PC, the greater the symptoms of anxiety and depression in the latter ${ }^{34,35}$.

The comorbidity of patients with CVD, such as diabetes, kidney failure, osteoporosis, cataracts, heart failure, and many more, is very important deleterious factors to consider in the quality of life of $\mathrm{PC}^{36}$.

Finally, a relevant aspect is an opposite effect, that is, the influence that the PC's quality of life exerts on the patient's quality of life. It has been found that all aspects of the SF-36 Health Survey aimed at evaluating the quality of life in the caregiver have a significant correlation with the measures of well-being and quality of life of patients with CVD?.

\section{Quality of life tests more frequently used in evaluating $P C$ of patients with cerebrovascular disease}

Quality of life is a complex construct that is composed of several domains that have not been yet sufficiently standardized. Therefore, various methods and tests have been developed for its evaluation. Table 1 shows some of the most frequently used assessment instruments, which included the WHOQOL-BREF ${ }^{4}$, SF-36 Health Survey $^{6}$, 12-Item Short Form Health Survey ${ }^{37}$, Ferrell linstrument $^{11}$, and the EuroQoL-5D (EQ-5D) ${ }^{38}$, emphasizing their theoretical foundation. Most of the tests are presented in self-administered formats and are intended to assess the subjective perception of various aspects of the physical and mental functioning of patients.

The physical aspect refers to the loss of energy, tiredness, fatigue, or difficulty in performing any physical activity and impact on work performance. All of them, activities that were previously carried out without problems, without pain, discomfort, or difficulty even resting, or sleeping. The mental aspect refers in most cases to symptoms of anxiety or depression, hope for recovery, contextualization of their current situation, self-esteem, self-perception, and limitations in activities of daily life due to emotional disorders.

Table 2 shows some of the main studies on quality of life in caregivers of patients with CVD and the tests used, as well as the most relevant findings.

\section{Discussion}

Risk factors, causes, diagnosis and acute treatment, mortality, secondary prevention, and physical and cognitive rehabilitation are usually studied in CVD, leading to few studies about the quality of life of their PC. It is known that the $1^{\text {st }}$ year is the most critical and challenging period for both the patient with CVD and his or her $\mathrm{PC}^{5,9,10 \text {. }}$

After reviewing the literature about quality of life in PC-PCVD, this work concludes the following: quality of life of PC-PCVD shows a significant impairment compared with non-caregivers ${ }^{7,8}$. Besides that, by being compared with the CVD patients under their care, patients exhibit lower scores in most quality of life domains in the acute phase; but a greater improvement over time. In other words, PC shows a worse prognosis and adaptability $5,10,14$.

Likewise, there is heterogeneity of quality of life domains as well as assessment tools. The outcome is an inherent inconsistency of results. Despite the heterogeneity of the quality of life concept, it was possible to find out the most common tests for its evaluation. In the first place, the WHOQOL-BREF, which mainly reveals a moderate to severe disturbance in quality of life of PC-PCVD. In addition, it shows a greater effect in areas as fatigue, mobility, and pain, sleep disturbances, meaning physical domain. In the second place, the SF36 Health Survey, which points out as the most affected domain the limitations in usual role activities because of emotional problems, meaning the role emotional of PC-PCVD $5,7,10,18$.

Being female, single, and older, with at least $3 \mathrm{~h}$ of care per day, with limited income, and anxiety or depression symptoms are the main characteristics associated with poorer quality of life in PC-PCVD. Although not all of the determinants of poor quality of life have theoretical explanations, some researches have a possible hypothesis. For example, it is proposed that caring hours does not imply a problem by itself, but rather the peripheral situations such as lack of leisure time or lack of social support network ${ }^{20}$. Likewise, it is referenced how limited income has a negative effect on the quality of life of PC through stress and worries rather than lack of supplies ${ }^{9,17}$.

Finally, it is mentioned that a married caregiver tends to have better support networks resulting in an inherent protective factor ${ }^{32}$. In several longitudinal investigations, the $1^{\text {st }}$ year has been determined to be the most complicated for PC-PCVD because of the number of abrupt changes ${ }^{5,10}$. While the quality of life 
Table 1. Quality of life assessment instruments more frequently used in primary caregivers of patients with cerebrovascular disease

\begin{tabular}{|c|c|c|}
\hline Quality of life instruments & Domains & Description of domains \\
\hline \multirow{4}{*}{$\begin{array}{l}\text { World Health Organization } \\
\text { Quality of Life BREF } \\
\text { (WHOQOL-BREF) }^{4}\end{array}$} & Physical & $\begin{array}{l}\text { Administration of medications, energy and fatigue, mobility, pain and } \\
\text { discomfort, sleep and rest, and capacity to work }\end{array}$ \\
\hline & Psychological & $\begin{array}{l}\text { Body image, appearance, negative feelings, self-esteem, spirituality, } \\
\text { religion, personal beliefs, thinking, learning, memory, and } \\
\text { concentration }\end{array}$ \\
\hline & Social & Social relationships, social support, and sexual activity \\
\hline & Environmental & $\begin{array}{l}\text { Finances, freedom, security, quality of health and social assistance, } \\
\text { domestic environment, recreation, traffic pollution }\end{array}$ \\
\hline \multirow{8}{*}{$\begin{array}{l}\text { Short Form } 36 \text { Health } \\
\text { Survey Questionnaire } \\
\text { (SF-36 Health Survey) }\end{array}$} & Physical functioning & Limitations in physical activities because of health problems \\
\hline & Physical role & Limitations in usual role activities because of physical health \\
\hline & Emotional role & Limitations in usual role activities because of emotional problems \\
\hline & Vitality & Energy or fatigue \\
\hline & Mental health & General mental health, i.e., psychological distress and well-being \\
\hline & Social functioning & $\begin{array}{l}\text { Limitations in social activities because of physical or emotional } \\
\text { problems }\end{array}$ \\
\hline & Bodily pain & Intensity of pain and its effect on daily life \\
\hline & General health & General health perception \\
\hline $\begin{array}{l}\text { 12-Item Short Form Health } \\
\text { Survey }^{37}\end{array}$ & $\begin{array}{l}\text { Reduced version of SF-36 } \\
\text { Health Survey. Includes the } \\
\text { exact same eight domains }\end{array}$ & $\begin{array}{l}\text { Usually used for large samples because its duration is } 2 \mathrm{~min} \\
\text { approximately }\end{array}$ \\
\hline \multirow[t]{4}{*}{ Ferrell Instrument ${ }^{11}$} & Physical & Functionality and general health \\
\hline & Psychological & $\begin{array}{l}\text { Personal characteristics as depression, fear, happiness and sense of } \\
\text { control }\end{array}$ \\
\hline & Spirituality & Meaning and purpose in life, hope, uncertainty, and significance \\
\hline & Social & $\begin{array}{l}\text { Interrelated components of quality of life including family distress, } \\
\text { social isolation, finances and sexual activity }\end{array}$ \\
\hline \multirow[t]{6}{*}{ EuroQoL-5D (EQ-5D) $)^{38}$} & Mobility & Walking, moving, being in bed \\
\hline & Self-care & Daily activities as bathing and getting dressed \\
\hline & Usual-activities & Working, cleaning, family time, and free time \\
\hline & Pain and discomfort & Physical or emotional pain \\
\hline & Anxiety and depression & Symptoms of anxiety and depression \\
\hline & \multicolumn{2}{|c|}{$\begin{array}{l}\text { It evaluates the five domains in five different levels: no problem, slight problem, moderate problem, } \\
\text { severe problem, and unable to. } \\
\text { In addition, it gives a ranking from } 0 \text { to } 100 \text { of general health perception }\end{array}$} \\
\hline
\end{tabular}

remains a vulnerable issue throughout disease evolution, surprisingly, improvements in the environmental domain (financial status, safety, quality of health and social services, home environment, recreation, pollution, and traffic) have been demonstrated after the $1^{\text {st }}$ year of the event ${ }^{9}$.
The majority of the reviewed articles were conducted in non-Spanish speaker population. As a matter of fact, the only investigation done in Latin America by Torres et al. $^{12}$, included a spirituality domain, being the most preserve aspect in PC-PCVD. This reflects the urgent need to analyze the quality of life in Latin countries. In 
Table 2. Factors for lower quality of life in primary caregivers of patients with cerebrovascular disease

\begin{tabular}{|c|c|c|c|c|}
\hline Reference & Sample (n) & Instrument & Most affected domains & Factors for PC lower quality of life \\
\hline $\begin{array}{l}\text { Jönsson et al. }{ }^{5} \\
(2005)\end{array}$ & $\begin{array}{l}304 \text { CVD } \\
\text { patients and } \\
234 \mathrm{PC}\end{array}$ & $\begin{array}{l}\text { World Health Organization } \\
\text { Quality of Life BREF } \\
\text { (WHO0OL-BREF) }\end{array}$ & Emotional role & $\begin{array}{l}\text { Being female, older age, lower } \\
\text { functionality, and lower social } \\
\text { participation of patient }\end{array}$ \\
\hline $\begin{array}{l}\text { Torres et al. }{ }^{12} \\
(2010)\end{array}$ & $97 \mathrm{PC}$ & Ferrell Instrument & $\begin{array}{l}\text { Social and physical } \\
\text { well-being }\end{array}$ & $\begin{array}{l}\text { Being female, older age and lower } \\
\text { incomes }\end{array}$ \\
\hline $\begin{array}{l}\text { McPherson } \\
\text { et al. }{ }^{7} \\
\text { (2011) }\end{array}$ & $56 \mathrm{PC}$ & SF-36 Health Survey & $\begin{array}{l}\text { Physical functioning, } \\
\text { Physical and } \\
\text { emotional role }\end{array}$ & $\begin{array}{l}\text { Older age either in caregiver and } \\
\text { patient. Perception of unbalanced } \\
\text { relationship for give-and-take } \\
\text { between caregiver and patient }\end{array}$ \\
\hline \multirow{4}{*}{$\begin{array}{l}\text { Costa et al. }{ }^{17} \\
\text { (2015) }\end{array}$} & \multirow[t]{4}{*}{$136 \mathrm{PC}$} & \multirow[t]{4}{*}{ SF-36 Health Survey } & Bodily pain & Younger age \\
\hline & & & Mental health and vitality & Lower income \\
\hline & & & Emotional role & Being single \\
\hline & & & Physical functioning & Being female \\
\hline $\begin{array}{l}\text { Haley et al. }{ }^{8} \\
(2015)\end{array}$ & $\begin{array}{l}235 \mathrm{PC} \text { and } \\
\text { CVD patients }\end{array}$ & $\begin{array}{l}\text { 12-Item Short Form Health } \\
\text { Survey }\end{array}$ & $\begin{array}{l}\text { All of them except } \\
\text { physical functioning }\end{array}$ & $\begin{array}{l}\text { Younger age, } \\
\text { lower education level, and health } \\
\text { problems }\end{array}$ \\
\hline $\begin{array}{l}\text { López-Espuela } \\
\text { et al. }{ }^{18} \\
(2015)\end{array}$ & $48 \mathrm{PC}$ & EuroQol-5D Questionnaire & $\begin{array}{l}\text { Pain and discomfort; } \\
\text { anxiety and depression }\end{array}$ & $\begin{array}{l}\text { Caring time and } \\
\text { Sleeping disorders }\end{array}$ \\
\hline $\begin{array}{l}\text { Chuluunbaatar } \\
\text { et al. }{ }^{9} \\
(2016)\end{array}$ & $\begin{array}{l}155 \text { CVD } \\
\text { patients y } 88 \\
\text { PC }\end{array}$ & $\begin{array}{l}\text { World Health Organization } \\
\text { Quality of Life BREF } \\
\text { (WHOQOL-BREF) }\end{array}$ & Physical domain & $\begin{array}{l}\text { Being female, poor health, and } \\
\text { financial difficulties }\end{array}$ \\
\hline \multirow[t]{2}{*}{$\begin{array}{l}\text { Efi et al. }{ }^{21} \\
\text { (2017) }\end{array}$} & \multirow[t]{2}{*}{$150 \mathrm{PC}$} & \multirow[t]{2}{*}{$\begin{array}{l}\text { 12-Item Short Form Health } \\
\text { Survey }\end{array}$} & Physical health & $\begin{array}{l}\text { Poor health, type of CVD; anxiety } \\
\text { and depression }\end{array}$ \\
\hline & & & Mental health & $\begin{array}{l}\text { Anxiety and depression; daily care } \\
\text { and patient's aphasia }\end{array}$ \\
\hline $\begin{array}{l}\text { Caro, Costa and } \\
\text { Da Cruz } \\
\text { (2018) }\end{array}$ & $30 \mathrm{PC}$ & $\begin{array}{l}\text { World Health Organization } \\
\text { Quality of Life BREF } \\
\text { (WHOQOL-BREF) }\end{array}$ & Social domain & Burden \\
\hline $\begin{array}{l}\text { Pucciarelli } \\
\text { et al. } .^{33} \\
(2018)\end{array}$ & $244 \mathrm{PC}$ & $\begin{array}{l}\text { World Health Organization } \\
\text { Quality of Life BREF } \\
\text { (WHOQOL-BREF) }\end{array}$ & Environmental domain & $\begin{array}{l}\text { Older age, lower education, } \\
\text { cohabitation with patient, lower } \\
\text { functional independence of the } \\
\text { patient }\end{array}$ \\
\hline
\end{tabular}

PC: primary caregivers; CVD: cerebrovascular disease.

spite of the inclusion of every type of CVD case for this review, it is clear a majority of ischemic CVD, coinciding with the higher prevalence showed in literature. All the investigations cited in this review analyzed several aspects of both PC and patients with CVD to understand the determinants of quality of life.

With regard to the patient, the main focus was on motor, independence, and speech disturbances; however, the variety of possible neuropsychological disturbances was ignored. This opens a path for future investigations. Finally, it is important to mention that every study used the quality of life concept in their description; however, the "health-related quality of life" concept turned out to be present in several test explanation. This finding might support future investigations about the difference between both concepts.

\section{Conclusion}

The quality of life of PC-PCVD is mainly affected in physical and emotional domains. Most of the analyzed studies highlight the importance of PC in the well-being of patients, such as their vulnerability. This leads to the proposal of broader and more controlled investigations. 
Studies about PC-PCVD are limited in our context despite its relevance. Prevention and intervention plans are urgently needed to improve quality of life.

The determinants of quality of life for PC-PCVD were summarized in seven sociodemographic characteristics of the caregiver: sex, age, caring hours, financial situation, relationship with the patient, anxiety and depression symptoms, and patient sequelae.

\section{Funding}

PNPC CONACYT supported this work.

\section{Conflicts of interest}

None.

\section{Ethical disclosures}

Protection of human and animal subjects. The authors declare that no experiments were performed on humans or animals for this study.

Confidentiality of data. The authors declare that no patient data appear in this article.

Right to privacy and informed consent. The authors declare that no patient data appear in this article.

\section{References}

1. Johnson W, Onuma O, Owolabi M, Sachdev S. Stroke: a global response is needed. Bull World Health Organ. 2016;94:634.

2. Schmidt SM, Herman LM, Koenig P, Leuze M, Monahan MK, Stubbers RW. Status of stroke patients: a community assessment. Arch Phys Med Rehabil. 1986;67:99-102.

3. Díez-Tejedor E, Alonso de Leciñana M, Hachinski V. Manejo del paciente con infarto cerebral en fase aguda. Rev Neurol. 1996;24:40-54.

4. Group W. The World Health Organization quality of life assessment (WHOQOL): position paper from the World Health Organization. Soc Sci Med. 1995;41:1403-9.

5. Jönsson AC, Lindgren I, Hallström BR, Norrving B, Lindgren A. Determinants of quality of life in stroke survivors and their informal caregivers. Stroke. 2005;36:803-8.

6. Ware JE Jr., Sherbourne CD. The MOS 36 -item short-form health survey (SF-36): i. Conceptual framework and item selection. Med Care. 1992;30:473-83.

7. McPherson CJ, Wilson KG, Chyurlia L, Leclerc C. The caregiving relationship and quality of life among partners of stroke survivors: A cross-sectional study. Health Qual Life Outcomes. 2011;9:29.

8. Haley WE, Roth DL, Hovater M, Clay OJ. Long-term impact of stroke on family caregiver well-being: a population-based case-control study. Neurology. 2015;84:1323-9.

9. Chuluunbaatar E, Chou YJ, Pu C. Quality of life of stroke survivors and their informal caregivers: a prospective study. Disabil Health J. 2016;9:306-12.

10. Pucciarelli G, Vellone E, Savini S, Simeone S, Ausili D, Alvaro R, et al. Roles of changing physical function and caregiver burden on quality of life in stroke: a longitudinal dyadic analysis. Stroke. 2017;48:733-9.

11. Ferrell B. La calidad de las vidas: 1525 voces del cáncer. ONS Bristol Myers. 1996;23:1-6.

12. Torres IE, Prieto AM, Lián AH. Calidad de vida de cuidadores de adultos con accidente cerebrovascular. Avances Enf. 2010;28:52-60.
13. Wan-Fei K, Hassan ST, Sann LM, Ismail SI, Raman RA, Ibrahim F. Depression, anxiety and quality of life in stroke survivors and their family caregivers: a pilot study using an actor/partner interdependence model. Electron Phys. 2017;9:4924.

14. Morimoto T, Schreiner AS, Asano H. Caregiver burden and health-related quality of life among Japanese stroke caregivers. Age Ageing. 2003;32:218-23.

15. Brajković L, Godan A, Godan L. Quality of life after stroke in old age: comparison of persons living in nursing home and those living in their own home. Croat Med J. 2009;50:182-8.

16. Klinedinst NJ, Gebhardt MC, Aycock DM, Nichols-Larsen DS, Uswatte G Wolf SL, et al. Caregiver characteristics predict stroke survivor quality of life at 4 months and 1 year. Res Nurs Health. 2009;32:592-605.

17. Costa TF, Costa KN, Fernandes MG, Martins KP, Brito SS. Quality of life of caregivers for patients of cerebrovascular accidents: association of (socio-demographic) characteristics and burden. Rev Escola Enf USP. 2015;49:245-52.

18. López-Espuela F, González-GilT, Jiménez-Gracia MA, Bravo-Fernández S, Amarilla-Donoso J. Impacto en la calidad de vida en cuidadores de supervivientes de un ictus. Enf Clín. 2015;25:49-56.

19. Caro CC, Costa JD, Da Cruz DM. Burden and quality of life of family caregivers of stroke patients. Occup Ther Health Care. 2018;32:154-71.

20. Jeong YG, Myong JP, Koo JW. The modifying role of caregiver burden on predictors of quality of life of caregivers of hospitalized chronic stroke patients. Disabil Health J. 2015;8:619-25.

21. Efi P, Fani K, Eleni T, Stylianos K, Vassilios K, Konstantinos B, et al. Quality of life and psychological distress of caregivers' of stroke people. Acta Neurol Taiwan. 2017;26:154-66.

22. Badaru UM, Ahmad BS, Lawal IU, Usman OO. Influence of duration of caregiving on the burden and quality of life of informal caregivers of stroke survivors. Int J Photon Optic Technol 2019;13:171.

23. Lurbe-Puerto K, Leandro ME, Baumann M. Experiences of caregiving, satisfaction of life, and social repercussions among family caregivers, two years post-stroke. Soc Work Health Care. 2012;51:725-42.

24. Sreedharan SE, Unnikrishnan J, Amal M, Shibi B, Sarma S, Sylaja P. Employment status, social function decline and caregiver burden among stroke survivors. A South Indian study. J Neurol Sci. 2013;332:97-101.

25. White CL, Mayo N, Hanley JA, Wood-Dauphinee S. Evolution of the caregiving experience in the initial 2 years following stroke. Res Nurs Health. 2003;26:177-89.

26. Ko JY, Aycock DM, Clark PC. A comparison of working versus nonworking family caregivers of stroke survivors. J Neurosci Nurs. 2007:39:217-25.

27. Savini S, Buck HG, Dickson VV, Simeone S, Pucciarelli G, Fida R, et al. Quality of life in stroke survivor-caregiver dyads: a new conceptual framework and longitudinal study protocol. J Adv Nurs. 2015;71:676-87.

28. Baumann M, Lurbe K, Leandro ME, Chau N. Life satisfaction of two-year post-stroke survivors: effects of socio-economic factors, motor impairment, newcastle stroke-specific quality of life measure and World Health Organization quality of life-bref of informal caregivers in Luxembourg and a rural area in Portugal. Cerebrovasc Dis. 2012;33:219-30.

29. Saldaña DM, Riaño HM, Rubiano LA, Rodríguez NM. Calidad de vida de los cuidadores de pacientes con enfermedades crónicas con parcial dependencia. Invest Enf Imagen. 2011:13:27-46.

30. Delcourt C, Hackett M, Wu Y, Huang Y, Wang J, Heeley E, et al. Determinants of quality of life after stroke in China: the ChinaQUEST (QUality evaluation of stroke care and treatment) study. Stroke. 2011;42:433-8.

31. Green TL, King KM. Functional and psychosocial outcomes 1 year after mild stroke. J Stroke Cerebrovasc Dis. 2010;19:10-6.

32. Bierhals CC, Low G, Paskulin LM. Quality of life perceptions of family caregivers of older adults stroke survivors: a longitudinal study. Appl Nurs Res. 2019;47:57-62.

33. Pucciarelli G, Ausili D, Galbussera AA, Rebora P, Savini S, Simeone S, et al. Quality of life, anxiety, depression and burden among stroke caregivers: a longitudinal, observational multicentre study. J Adv Nurs. 2018;74:1875-87.

34. Rohde D, Gaynor E, Large M, Conway O, Bennett K, Williams DJ, et al. Stroke survivor cognitive decline and psychological wellbeing of family caregivers five years post-stroke: a cross-sectional analysis. Top Stroke Rehabil. 2019;26:180-6.

35. Atteih S, Mellon L, Hall P, Brewer L, Horgan F, Williams D, et al. Implications of stroke for caregiver outcomes: findings from the ASPIRE-S study. Int J Stroke. 2015;10:918-23.

36. Icks A, Claessen H, Morbach S, Glaeske G, Hoffmann F. Time-dependent impact of diabetes on mortality in patients with stroke: survival up to 5 years in a health insurance population cohort in Germany. Diabetes Care. 2012;35:1868-75.

37. Ware JE Jr., Kosinski M, Keller SD. A 12-item short-form health survey: construction of scales and preliminary tests of reliability and validity. Med Care. 1996;34:220-33.

38. Group TE. EuroQol-a new facility for the measurement of health-related quality of life. Health Pol. 1990;16:199-208. 